\title{
Progress in the research on the mechanism of bone metastasis in lung cancer (Review)
}

\author{
QINQIN LUO ${ }^{1}$, ZHENYE XU $^{2}$, LIFANG WANG ${ }^{2}$, MINGYU RUAN $^{1}$ and GUIYU JIN ${ }^{1}$ \\ ${ }^{1}$ Department of Postgraduates, Shanghai University of Traditional Chinese Medicine, Shanghai 201203; \\ ${ }^{2}$ Department of Oncology, Longhua Hospital Affiliated to Shanghai University of \\ Traditional Chinese Medicine, Shanghai 200030, P.R. China
}

Received December 4, 2015; Accepted April 28, 2016

DOI: $10.3892 / \mathrm{mco} .2016 .917$

\begin{abstract}
Lung cancer is still the predominant cause of cancer-associated mortality worldwide. The bone metastasis of lung cancer brings great suffering to the patient. Previous advances have provided insights into the mechanism of bone metastasis. Previous research has investigated lung cancer stem cells and three steps were determined for the lung cancer cells to metastasize to the bone: i) Escaping from the primary tumor; ii) moving in the circulation; iii) colonizing in the bone. Key molecules are involved in each of these process. Although there is a close association and similarity, dynamic microenvironments affect these processes. The receptor activator of nuclear factor- $\kappa \mathrm{B}(\mathrm{RANK}) / \mathrm{RANKL}$ axis serves a vital role in the regulation of the generation and activation of osteoclasts during the osteolytic lesion. However, the specific molecules for the lung cancer cells to metastasize to the bone require further research and exploration. The present study aimed to investigate the relative molecular mechanisms of bone metastasis in lung cancer in recent years, providing a general understanding about the features of lung cancer preferences to bone, and discussing other things that require investigation.
\end{abstract}

\section{Contents}

1. Introduction

2. The 'seed' - lung cancer stem cells

3. Escaping from the primary tumor

4. Moving in the circulation

5. Colonizing in the 'soil' - bone

6. Conclusions

Correspondence to: Mr. Zhenye Xu, Department of Oncology, Longhua Hospital Affiliated to Shanghai University of Traditional Chinese Medicine, 725 Wan Ping South Road, Xujiahui, Shanghai 200030, P.R. China

E-mail: xuzhenye1947@126.com

Key words: lung cancer, bone metastasis, lung cancer stem cells, microenvironment, osteoclast

\section{Introduction}

Nowadays, as a result of the vast development of therapeutic intervention in lung cancer, including targeted therapy, thousands of patients have a longer overall survival and an improved quality of life. Although lung cancer remains the leading cause of cancer-associated mortality worldwide, the mortality of the malignant tumor has reduced slightly $(1,2)$. Notably, metastasis is responsible for as much as $90 \%$ of cancer-associated mortality. Lung cancer exhibits a strong predilection to develop to bone metastasis, which would bring not only physical torment, including pain, broken bones and spinal compression, but also the mental affliction to the patients, which greatly reduce the quality of life and overall survival of the patients $(3,4)$. Despite the fact that the medical management of bone metastases in lung cancer has made great progress, the effective curative clinical therapy is limited (5). Additionally, the mechanism regarding bone metastasis remains poorly understood in the pathogenesis of lung cancer. In order to have a general understanding of the mechanisms of bone metastasis in lung cancer, the present review outlined the relative previous studies and suggested the possible mechanisms involved.

According to accumulating evidence, the bone marrow is one of the most common places for the lung cancer cells to metastasize (6). With the bone organophilic phenomenon, Paget's 'seed and soil' hypothesis may provide certain reasonable explanation (7). However, contrary to the passive course of the seed planted into the soil, it is an active process for the lung cancer cells colonize ('seed') in the bone marrow ('soil'), under the driving effect of multiple molecules, signaling pathways and cells. Bone metastasis in lung cancer is the completion of a complex succession of cell-biological events, in which there are multiple interactions of cancer cells with host cellular and extracellular microenvironments being involved, as well as different types of molecules, including cytokines (8), adhesion molecules, hormones (9) and chemokines $(10,11)$. It was demonstrated that three types of lesions exist in bone metastases, osteoblast-mediated bone formation, osteoclast-mediated bone resorption and a mixture of each (12). The osteolytic lesion is predominant in the bone metastasis of lung cancer. The present review aimed to introduce the functions of various molecules involved in different processes of 
bone metastasis in lung cancer. Considering of the 'seed and soil' hypothesis, the present review will begin with the 'seed', the lung cancer cell, and discuss its metastatic potential.

\section{The 'seed' - lung cancer stem cells}

A large quantity of experimental evidence supports there being a group of cells in the tumor exhibiting the ability of self-renewal, multilineage differentiation and superior levels of malignancy. These cells may be termed cancer stem cells (CSCs) $(13,14)$. It has been experimentally demonstrated that the CSCs exist in an unperturbed solid tumor (15). CSCs have been identified in breast (16), colon (17,18), pancreatic (19), prostate (20-22) and brain cancer (23). Additionally, CSCs have been identified and isolated from lung cancer, and it was demonstrated that the lung CSCs express tissue-specific cell surface markers, including cluster of differentiation (CD)133+ (24). In addition, these lung CSCs are thought to have high drug resistance and tumorigenicity, owing to tumor regeneration following chemotherapy $(25,26)$. For this reason, certain scholars have selected the lung CSCs which expressed tissue-specific cell surface markers, including CD133, CD117 and nuclear $\beta$-catenin, and do not express differentiation markers, including cytokeratin (CK)8/18. It was revealed that these CSCs, through an efficient cytokine network production, have high tumorigenic and metastatic potentials (27).

However, with the exception of intrinsic CSCs, the neighboring cancer cells may acquire CSC-like characteristics under the interaction with the active stroma (28). The epithelial-to-mesenchymal transition (EMT) is a cell-biological program, in which the epithelial cells change to exhibit the traits of cells disseminating from primary tumors and seeding metastases (29-31). Experimental data has revealed that the non-CSCs can be induced to enter into a CSC-like state via the EMT $(32,33)$. However, the induced CSCs may well lapse back to a fully epithelial state without CSC function (34). To a certain extent, the transformation of the tumor cells may not completely allow the cells to obtain the function of CSCs, therefore, they may be in the stage between the epithelial cell and induced CSCs (35). In order to study the biology of migrating CSCs, the epithelial-specific and cell-surface markers involved in the EMT are used to detect the circulation tumor cells (CTCs) (36-38). Using a blood filtration approach in patients with lung cancer, Hou et al (39) observed the CTCs lost the expression of E-cadherin, while obtained the expressing of the vimentin, indicating that the CTCs performed a feature of EMT, when the CSCs or induced CSCs enter into the circulation (39).

Despite this, no definite evidence exists to affirm that it is the CSCs that launch the distant metastasis. Considering the ability of self-renewal, multilineage differentiation and superior levels of malignancy, it is generally thought the CSCs are the 'seed' to plant into the distant 'soil'. Whether certain lung CSCs perform the bone organophilic property requires further investigation.

\section{Escaping from the primary tumor}

Tumor cells escaping from the tumor mass. Prior to the metastases, the tumor cells are tightly bound to neighboring cells and to the underlying basement membranes through adheren junctions, tight junctions, desmosomes and hemi-desmosomes.
These tight physical constraints immobilize the cells effectively as a whole. As the carcinoma progresses, the tumor cells have to break away from the constraints, preparing for metastases.

Initially, the intercellular adhesion molecule changes the features of the adhesion between the tumor cells that make the tumor cells remove themselves from the tumor cell mass. Numerous types of adhesion molecules exist, in which the E-cadherin is a direct mediator of intercellular adhesion. Reduction of E-cadherin causes the tumor cells to invade and metastasize early (40). In a meta-analysis of non-small cell lung cancer (NSCLC), the reduction or lack of E-cadherin represented the high motility of the tumor cells and indicated a poor prognosis (41).

It has also been revealed that it is necessary, although not sufficient, for the EMT to reduce the E-cadherin function, which enables the detachment and reorganization of epithelial-cell sheets in tumor invasion and metastasis $(42,43)$. It was previously observed in A549 cells that transforming growth factor (TGF)- $\beta 1$ induces the EMT by upregulating the expression of mesenchymal markers, including vimentin and Slug, and downregulating the levels of epithelial markers, including E-cadherin and cytokeratins (44). Zeb1 and Snaill negatively regulate the expression of E-cadherin (28), and a previous study demonstrated that Wnt signaling can accelerate bone metastasis in a lung cancer model via the upregulation of Snail1 and Zeb1, and down-regulating E-cadherin (45).

Besides E-cadherin, selectins and integrins are involved in the process of the dissociation of the tumor cells from the mass. The successful dissociation is the result of the cooperation of these molecules, thus, more studies are required to analyze the complex mechanism in the bone metastasis of lung cancer.

Tumor cells breaking away from the ECM. When the carcinoma cells break-away from the tumor mass, they have to pass through the extracellular matrix (ECM), a structural framework consisting of fibrous proteins and proteoglycans (46). Firstly, the cells must traverse the basement membrane (BM), a specialized ECM, and subsequently invade the adjacent stromal compartments. The proliferation of the tumor forms a microenvironment where the tumor cells interact with various cell types within the ECM, including the endothelial cells, tumor-associated macrophages (TAM) and fibroblasts (47). For instance, under the stimulation of tumor-derived colony stimulating factor 1 , the TAM not only proliferate, but also produce growth factors, including fibroblast growth factor, epidermal growth factor receptor ligands and platelet-derived growth factor (PDGF), and proteases, including matrix metalloproteinases (MMPs) and the cathepsins (48).

Various types of proteinases degrade the ECM for distant metastasis, while the MMPs, including MMP2 and MMP9 (49), are regarded as the major enzymes to make the ECM. It was revealed that MMP9 and MMP13 are involved in mediating cell migration and invasion in NSCLC (50). Additionally, previous clinical research (51) revealed that with the expression of MMP13, the carcinoma cells of NSCLC patients are found more easily in the bone marrow, indicating that MMP13 may be one of the predictive factors for the patients with NSCLC that may develop bone metastasis. It has 
been reported that miRNA (miR)-29c suppresses the adhesion of lung cancer cells to the ECM and their metastasis by targeting integrin $\beta 1$ and MMP2 (52). Currently, in the field of bone metastasis in lung cancer, the degradation mechanism predominantly focused on the MMPs, which perform the similar effect in other cancer types.

\section{Moving in the circulation}

Intravasation of the tumor cells. As mentioned above, endothelial cells exist in the microenvironment within the ECM, which are attracted by the angiogenic stimuli produced by the tumor cells to migrate (53). Under the synthetic action of several signaling pathways, including vascular endothelial growth factor (VEGF), hypoxia-inducible factors and Notch, and several ECM proteins, the endothelial cells gradually build the new blood vessels (54), which provide a highway for the tumor cells to metastasize to distant sites. The induced blood vessels are generally leaky, with weak cell-cell junctions, and the tumor cells can enter vasculature through the crack easily (55).

Beyond the new blood vessels, the tumor cells exit the ECM and arrive at the intrinsic vessels. Similar to the degradation of the BM, the tumor cells produce proteases to break-down the basement membrane outside of the vessels, then with the motility to adhere to the endothelial cells. Finally, the tumor cells enter into the vasculature with the ameboid movement.

When the carcinoma cells enter into the circulatory system, they can be termed circulating tumor cells (CTCs), which are so rare that they are found at a frequency as low as 1 CTC per 106/7 leukocytes, with much lower numbers in early stage disease (56). However, numeorus studies have indicated that CTCs offer the prospect of under-key intermediaries between the primary site and metastases $(57,58)$. Although CTCs are extremely rare in the circulation, they can be detected even prior to the definitive diagnosis of lung cancer, as well as at other stages (59). Increasing clinical evidence in lung cancer has shown that the counts of the CTCs have a significant association with a worse prognosis (60-62). Additionally, it is popularly hypothesized that the metastasis has an intimate association with the circulating tumor microemboli (CTM). As an aggregate of CTCs, the CTM is either associated with other tumor cells or associated with fibroblasts, leukocytes, endothelial cells or platelets (63), which assist with avoiding the destruction of the immune system in the circulation, as well as to assist tumor cells extravasation (64). In a previous pilot study, the CTM was found not only in patients with samll cell lung cancer (SCLC), but also in NSCLC. In comparison with CTCs, CTM has a higher propensity to metastasize, and the cardinal feature of EMT has been observed in the majority of CTM in patients with lung cancer (65). In SCLC, P-selectin can induce the combination of the SCLC cells and activated platelets, therefore facilitating the formation of the CTM (66).

According to these previous studies, it may be hypothesized that when the tumor cells permeate into the vessels, certain components of the blood combine with the tumor cells and convoy them to the target organs, which from a dynamic microenvironment for the tumor cells in the circulation.

Oriented moving in the circulation. According to the routine, the tumor cells in the circulation will move with the blood- stream and they will have the same chance to metastasize throughout the whole body. However, this may not to be the case. In lung cancer, the tumor cells have a preference for the bone (67), as well as the brain, liver and adrenal gland. Previous experimental research has demonstrated that sites of metastasis are co-determined by the characteristics of carcinoma cells and the microenvironment of the target organ (68), the precise molecules and mechanism of oriented metastasis remain to be explained fully. However, it has been demonstrated that the target organs can attract the cancer cells from the primary lesion through chemotactic factors (69). The mutual attraction between the chemokine and relative receptors serves a vital role in tumor cell tropism.

C-X-C motif chemokine (CXCL)12 (stromal cell-derived factor-1) and its receptor $\mathrm{C}-\mathrm{X}-\mathrm{C}$ chemokine receptor (CXCR) 4 are thought to regulate the metastasis of breast cancer, particularly bone metastasis (70-72). The role of the CXCL12-CXCR4 chemokine axis has also has been revealed not only in the murine model, but also in the patients of bone metastasis of lung cancer. The lung cancer cells expressing CXCR4 are attracted to the bone and other target organs though the chemotactic gradients, for the concentration gradients of the CXCL12 exist between the primary tumor, plasma and organ sites of metastases (73). However, this axis appears to have effects in both target organs in lung cancer, not just the bone. It is very contradictory that, when the CXCR4 is genetically disrupted, the osteoclast activity would be elevated rather than suppressed, and the tumor cells in the bone proliferate faster (74). Additionally, it is reported that the interruption of this chemokine axis may bring destruction to the immune system or cause metastasis to the other target organs (75). Therefore, even though the CXCL12-CXCR4 chemokine axis serves a vital role in guiding the tumor cells to the target organs, the therapeutic strategies aiming at this axis may easily cause further issues.

When investigating SCLC, Nakamura et al (76) found that $\mathrm{C}-\mathrm{C}$ motif chemokine 22 expressed by the osteoclasts induced the motility and invasion of the SBC-5 cells through the integration with the $\mathrm{C}-\mathrm{C}$ motif receptor 4 expression on the surface of SBC-5 cells. Therefore, whatever type of lung cancer, the chemokine has a great effect in the target organs metastasis, and with regards to bone metastasis, whether there are exclusive factors that induce the oriented move require further elucidation.

Besides this well-studied 'classical' chemokine axis, several novel chemokines have been recently identified in tumor bone metastasis. CXCR7 has been uncovered as a second CXCL12 receptor, which performs a similar function to CXCR4 in tumor development (77). In addition, CXCL10 has been reported to facilitate the trafficking of CXCR3-expressing cancer cells to the bone (78). The effect of these novel factors in lung cancer bone metastasis require further elucidation.

Extravasation of the tumor cells. When the tumor cells are attracted to the capillaries of the target organs, they will prepare to pull in to the organ and dock here. It is generally hypothesized that the extravasation of the tumor cells is similar with the trans-endothelial migration of the leukocytes to the inflammation area, including the pulling over, slowing down, attaching to the wall, rolling and moving out. 
Under the attraction of the P-selectin and E-selectin of the endothelial cell, the tumor cells must move slowly, and subsequently adhere to the endothelial cells following combination with the integrins through the arginine-glycine-aspartic acid peptide. At last, the tumor cell-activated platelets induce the opening of the endothelial barrier, allowing tumor cells to migrate trans-endothelially (64). Therefore, the tumor cells will exit from the vessels with ameboid movement. During this process, the adhesion of the tumor cells to the endothelial cells is the critical step, and the adhesion molecules serve an important role in this. Various types of adhesion molecules, including the CD44 family, integrin family and the selectins. The majority of these cooperate to take part in the bone metastasis of lung cancer.

Integrin is a type of cell surface receptor, which interacts with the ECM and mediates intracellular adhesion. It has a high expression pattern in the malignant cell surface and its expression is positively correlated with the motility of the tumor cells. Li et al (79) observed that, compared with the SBC-3 cells with low bone metastasis potential, the SBC-3 with high bone metastasis potential exhibited a higher expression of the $\beta 3$-integrine. When the SBC- 3 cells were interrupted with small interfering RNA against $\beta 3$-integrine, the adhesion, motility and invasion was significantly reduced (79). CD44 induced the adhesion through the combination with the hyaluronic acid (HA), collagen and laminin. It is recognized as a potential cancer stem cell marker (80), and has also been suggested to promote bone metastasis by enhancing the production of HA, tumorigenicity and cell motility (81). The upregulation of the CD44 gene of the human lung squamous cancer cell HARA was identified, which was co-cultured with the skull of the newborn mice (82). In a bone metastasis model of nude mice injected with SBC- 5 cells, a considerable number of osteoclasts expressing CD44, markedly positive for osteopontin in the stromal tissues of the metastatic lesion were observed, which implied that the osteopontin may serve to facilitate osteoclast migration with CD44 (83). This indicated that CD44 not only served a vital role in the course of the adhesion of lung cancer cells to the bone, but was also involved in the course of the osteolysis.

During this process, when the tumor cells move in the circulation, the tropism movement is the special and unique feature of the bone metastasis in lung cancer. The chemokine and associated receptors are the helmsman, leading the tumor cells to the target organs. Until now, the specific chemokine involved remains to be elucidated.

\section{Colonizing in the 'soil' - bone}

According to the anatomy and pathology, the tumor cells would be arrested in the bone marrow with the bloodstream in the bone metastasis, then they have to egress from the central sinus of the bone marrow. Following the attachment to bone surfaces, the tumor cells induce osteolytic bone destruction in conjunction within the bone microenvironment, and colonize in the bone (84). The bone metastasis of lung cancer predominantly occurs at the spinal bone, ribs, sternum, and the tips of the long bone where there are special micro-sinuses. These sinuses provide good access for the tumor cells to exude from the vessels. The wide-diameter and slow bloodstream of the sinus are better for the tumor cells to travel though and adhere to the endothelial cells. The sinus has a special structure, which is composed of endothelial cells with broad intercellular space, and the tumor cells can easily egress from the sinus and then attach to the bone.

Attachment to the bone. The tumor cell attachment and lodgment in the bone are complex processes, which are actively driven by specific interactions between tumor and normal cells, and with the ECM components of the osseous milieu. Prior to the tumor cells to joining in the osseous milieu, the attachment to the perimyelis is the first step. Certain adhesion molecules are involved in this step, including vascular cell adhesion protein-1, $\alpha 4 \beta 1$ integrin and cadherin-11 (84).

Notbaly, MGr1-Ag demonstrates high laminin-binding activity and it was observed that compared with the expression in cells without bone-metastatic ability (SBC-3 cell line), MGrl-Ag was highly expressed in bone-metastatic SCLC cells (SBC-5 cell line). In addition, MGr1-Ag promotes SCLC cell invasion and bone metastasis both in vitro and in vivo via the EMT pathway (85). Discoidin domain receptor-1 (DDR1) is a collagen receptor highly expressed in invading tumor cells and mediates tumor cell survival in bone metastasis (86). Karmele et al (87) found that disruption of DDR1 hampers lung cancer cell survival, leading to impaired early tumor-bone engagement during skeletal homing, and crucially altering bone colonization. PDGF is secreted from the bone stroma. Previous studies have found that the disruption of the PDGF receptor in the bone marrow stroma prevents efficient engagement required for bone homing and osseous colonization, by altering heterotypic tumor-stromal and tumor-matrix interactions (88).

Osteoclastic bone destruction. Once the tumor cells land on the bone successfully, the tumor cells join with the bone cells and began to interact with the local bone microenvironment with numerous different types of cells, including osteoclasts, osteoblasts, osteocytes, macrophages and adipocytes. Under the interaction with several molecules and signaling pathways, the tumor cells can construct a hospitable environment for survival and proliferation.

In the pathophysiology of bone metastasis, multiple evidence has demonstrated that it is the osteoclast that destroys the bone, rather than the tumor cells $(89,90)$. As with the bone metastasis of lung cancer, the destruction of the bone is primarily the soluble osseous, in which the osteoclast is the arch-criminal. In this osteolytic lesion, the tumor cells promote osteoclast formation by continuingly secreting pro-osteoclastogenic factors, including parathyroid hormonerelated protein $(\mathrm{PTHrP})$, receptor activator of nuclear factor- $\kappa \mathrm{B}$ (RANK)L and macrophage colony-stimulating factor. Simultaneously, the excessive generation of abnormally activated osteoclasts elevate the bone resorption, in which the growth factors, including TGF- $\beta$, insulin-like growth factors (IGFs), PDGFs and bone morphogenetic proteins, are released from the bone matrix. As a result of that, the abundant growth factors provide a rich 'soil' for the tumor cells to proliferate. Additionally, the destruction of the bone matrix supply provides more room for the tumor cells to expand. Therefore, this tumor-osteoclast cooperation forms a vicious cycle in the 


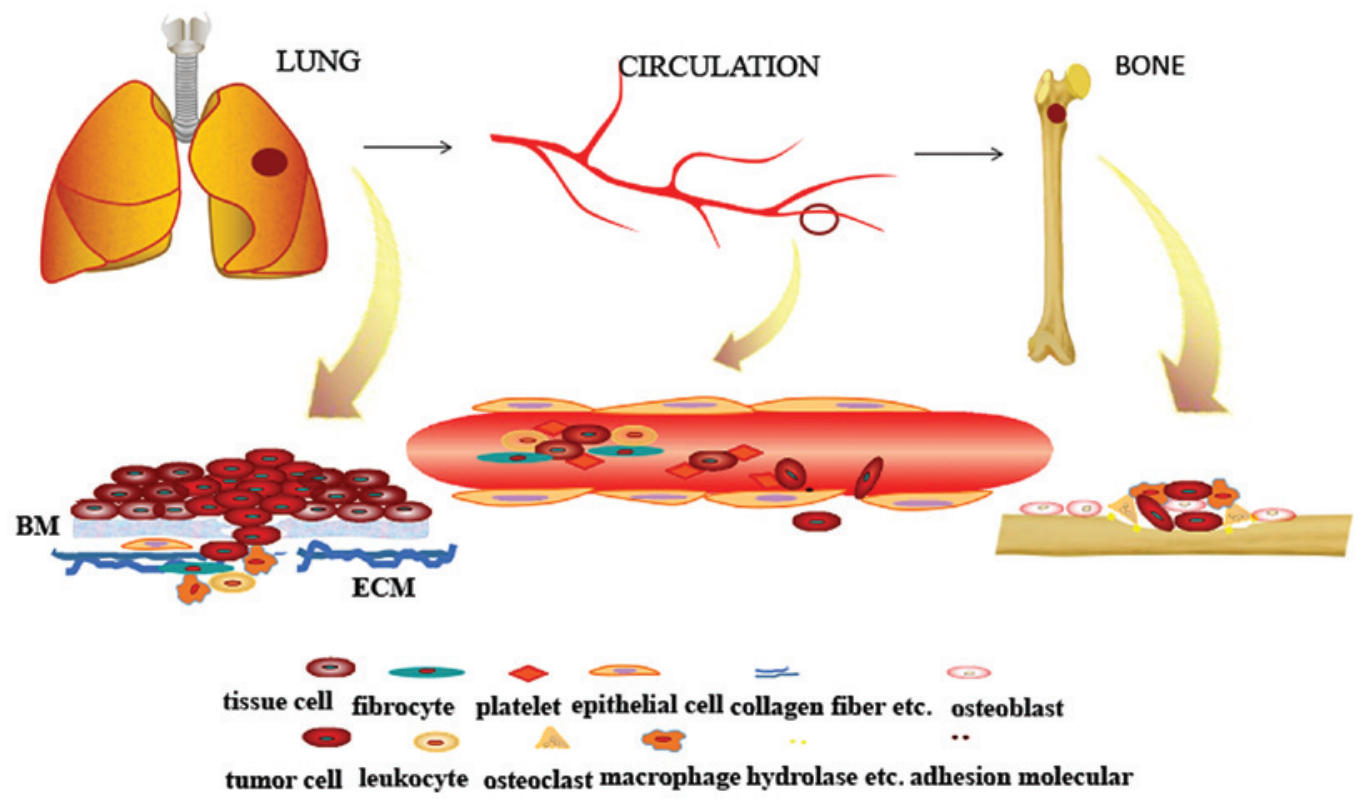

Figure 1. A schematic of the three Sites and microenvironments of the lung cancer cells in the bone metastasis. The first step is the escape of the tumor cells from the primary tumor. In this step, ICAM is vital, and in particular, E-cadherin. The second step involves the cells moving in the circulation and the successful movement to the bone under the guidance of chemokine. In the final step, the cells colonize in the bone. At this stage, the tumor cells interact with the neighboring cells to destroy the bone. The tumor cells transfer within a dynamic microenvironment to the bone. BM, basement membrane; ECM, extracellular matrix.

bone microenvironment, accelerating the bone injury, as well as the pain (91). Therefore, the metabolism of the osteoclast is becoming the critical point to research the development of the osteolytic lesion. Notably, multiple molecules and signaling pathways are involved in this process in conjunction with tumor cells, osteoblasts and other cell types in the bone microenvironment, while the key signaling pathway is the osteoprotegerin (OPG)/RANK/RANKL axis.

A balance exists between the osteoclastic bone resorption regulated by the osteoclast, and the osteoblastic bone formation dominated by the osteoblast in the bone metabolism. Additionally, it is widely hypothesized that the OPG/RANK/RANKL axis is the primary factor to regulate this balance. The osteolytic metastatic lesion is the result of the fact that the osteoclastic bone resorption supersedes the osteoblastic bone formation, indicating that the axis is out of balance. It has been previously reported that the soluble RANKL and OPG in the serum are elevated in lung cancer patients with bone metastases (92), indicating that the axis serves a role in the bone metastasis of lung cancer. In samples from patients with bone metastasis of NSCLC, it was demonstrated that the upregulation of OPG, RANK and RANKL, and the increase in the ratio of RANKL/OPG occurred. In vitro, the NSCLC cells with transfection of RANKL cDNA exhibited higher motility and invasion, while the ability reduced following the addition of OPG (93). When inhibiting the RANK-RANKL interaction, the osteolytic lesion induced by the NSCLC cell line A549 in SCID mice was limited (94).

Notably, an abundance of molecules have been revealed to take part in the regulation of the axis, including prostaglandin E, parathyroid hormone, TGF- $\beta$, interleukin-1, tumor necrosis factor- $\alpha$ and PTHrP. Of these, PTHrP has been identified to serve a vital role in the bone metastasis of breast and prostate cancer $(95,96)$.
In addition, there is popular belief that PTHrP may be one of the unique regulatory factors involved in the bone metastasis of lung cancer (97). Positive expression of PTHrP in lung cancer indicated a higher chance for the development of the bone metastasis, and researchers also revealed that the PTHrP produced by the lung cancer cells may induce the osteoblasts to express the RANKL, as well as reduce the generation of OPG, leading to osteoclast maturation and activation (98). Miki et al (9) repeatedly injected the neutralizing antibody of PTHrP into the SCLC model mice and found that the bone metastasis was markedly suppressed (9). It was revealed that a highly bone metastatic lung squamous cell carcinoma cell line (HARA) overexpressed PTHrP, and that the treatment of nude mice with anti-PTHrP antibody inhibited the formation of bone metastasis (99). The TGF- $\beta$ can also stimulate the lung cancer cells to overexpressing PTHrP and if the TGF- $\beta$ signaling pathway was suppressed, the PTHrP expression was also reduced (100). Therefore, it is clear that the different cytokines can interact or influence each other, and their complex association constitutes a web to regulate the bone metastasis microenvironment. Deng et al (82) analyzed the gene expression levels in the HARA human lung squamous cancer cell line, which exhibits a high bone metastatic tendency, and demonstrated that besides PTHrP, ezrin was also expressed at a higher rate in the bone metastasis lesion (82).

Apart from the osteoclasts, researchers also pay increasing attention to the macrophages in the tumor microenvironment, as well as in the bone metastasis (101). Macrophages are derived from myeloid progenitors and are an important component of the bone marrow. This cell type can be classified into two main subsets: M1 macrophages, generally promoting inflammation, and M2 macrophages, typically suppressing inflammation and assisting tissue repair (102). Within the tumor microenvironment, M1 macrophages have been proposed to be antitumorigenic and 
kill cancer cells. By contrast, the M2 macrophages are generally considered to be pro-tumorigenic by releasing a variety of growth factors, including fibroblast growth factors and VEGF, to promote tumor growth and invasion (103). Hiraoka et al (104) broadly assessed the effects of monocytes and macrophages in a metastatic lung cancer cell cardiac injection mouse model. When they depleted monocytes and macrophages with clodronate-packaged liposomes, they found that targeting both macrophages and osteoclasts revealed a more pronounced reduction in the number and size of bone metastatic lesions compared with the sole osteoclast-targeting agent, reveromycin A (104).

In the bone microenvironment, besides the osteoclasts and macrophages, other cells (osteoblasts and adipocytes), are also in conjunction with the tumor cells to develop the osteolytic lesion (105), as well as several different approaches and molecules. Despite of the complex process in the bone metastasis of lung cancer, numerous researchers are investigating a specific critical cell or molecule involved in this. For instance, receptor of activated protein $\mathrm{C}$, histone deacetylase 4, paired-like homeodomain 1, roundabout axon guidance receptor homolog 1 and Wnt/T cell factor signaling perform a negative function in bone metastasis of lung adenocarcinoma (106-109). Additionally, increasing attention is being paid to the miR involved in the bone metastasis of lung cancer. Valencia et al (110) found that miR-326 was a relevant biomarker representative of osteolysis in the model of bone metastasis in lung cancer. It was observed that systemic delivery of miR-192 can decrease osteolytic lesions in a lung cancer mouse model (111). In SBC-5 cells, the loss of miR335 promoted SCLC metastatic bone lesion by reducing the expression levels of RANKL and IGF-IR (109).

\section{Conclusions}

Compared with the osteolytic bone metastasis in lung cancer, the osteoblastic bone metastasis is seldom observed clinically, therfore, relative research is limited. Although the osteolytic lesion is most frequently observed clinically, osteoblastic bone metastasis and the mixed bone metastasis occur in patients with lung cancer (112). In addition, the bone lesion in the patients with NSCLC is predominantly osteolytic (105). By contrast, SCLC is mostly osteoblastic. However, the mouse model of bone metastasis in lung cancer was used to assess pathological changes in osteoclstic lesion. Therefore, attention must be paid to select the proper models to analyze the bone metastasis in lung cancer.

The process of the bone metastasis in lung cancer can be divided into three steps: i) Escaping from the primary tumor; ii) moving in the circulation; iii) colonizing in the bone. In each of these mechanisms, this process is continuous and progressive, coordinating and complex. Certain molecules will be involved in the different steps with different effects. For instance, when the lung cancer cells leave the primary lesion, the decrease of the adhesion molecules contribute to its dissociation with the neighbor cells. Additionally, the tumor cells moving in the circulation also demand adhesion and dissociation with the endothelial cells. In addition, when attaching to the bone, the tumor cells require the assistance of the adhesion molecules. Therefore, the adhesion and dissociation regulated by the adhesion molecules perform an essential rold during the entire metastatic process. Notably, with the exception of the adhesion molecules, numerous other molecules are cooperating to accomplish each step. It is similar for the lung cancer cells to metastasize to other target organs in the former two steps. Although there are chemokines leading to the bone metastasis in the early steps, they reveal no specificity of bone metastasis. Therefore, the most specific and unique is the third step in bone metastasis of lung cancer. In this process, under the interaction with tumor cells, the osteoclast regulates the osteolytic lesion. In this stage, numerous signaling pathways and molecules are involved. The most important and critical pathway is the RANK/RANKL axis. This has been studied in depth in the field of bone metastasis and diphosphonate treatment targeting this axis has been clinically applied. However, there is no way to delay or stop the occurrence of the bone metastasis and the side-effect of diphosphonate, mandible necrosis, has no effective treatment. In addition, the exact molecules and mechanism of this axis in bone metastasis of lung cancer requires more investigation.

As shown in Fig. 1, from the primary tumor to the circulation and finally, the settling down in the bone, the tumor cells are living in a microenvironment in each site, therefore the tumor cells can generate, invade, escape from the immune system, and obtain more nutrition and space to expand. Therefore, the smart 'seed' applies the collective strength from the neighbor cells to trudge to the rich 'soil'. This indicates that the enemy is more than the tumor cells in the battle to fight with the bone metastasis. Thus, more attention should be paid to the entire microenvironment. Nowadays, with the improvement of the therapy in lung cancer, patients with lung cancer have a longer survival time. Therefore, how to prevent the bone metastasis prior to the late stage is becoming very important. Further investigations and in depth studies must be performed to determine how to prevent the bone metastasis in the earlier stages of lung cancer.

\section{References}

1. Salomaa ER and Walta M: The prognosis of lung cancer continues to be poor-treatment outcome within the hospital district of Southwest Finland in 2004 to 2011. Duodecim 131: 69-75, 2015 (In Finnish).

2. GLOBOCAN: Estimated cancer incidence, mortality and prevalence worldwide in 2012. IARC, 2014.

3. Hirsh V, Major PP, Lipton A, Cook RJ, Langer CJ, Smith MR, Brown JE and Coleman RE: Zoledronic acid and survival in patients with metastatic bone disease from lung cancer and elevated markers of osteoclast activity. J Thorac Oncol 3: 228-236, 2008.

4. Mundy GR: Metastasis to bone: Causes, consequences and therapeutic opportunities. Nat Rev Cancer 2: 584-593, 2002.

5. Taubenberger AV: In vitro microenvironments to study breast cancer bone colonisation. Adv Drug Deliv Rev 79-80: 135-144, 2014.

6. Hess KR, Varadhachary GR, Taylor SH, Wei W, Raber MN, Lenzi R and Abbruzzese JL: Metastatic patterns in adenocarcinoma. Cancer 106: 1624-1633, 2006.

7. Paget $S$ : The distribution of secondary growths in cancer of the breast. 1889. Cancer Metastasis Rev 8: 98-101, 1989.

8. Uy HL, Mundy GR, Boyce BF, Story BM, Dunstan CR, Yin JJ, Roodman GD and Guise TA: Tumor necrosis factor enhances parathyroid hormone-related protein-induced hypercalcemia and bone resorption without inhibiting bone formation in vivo. Cancer Res 57: 3194-3199, 1997.

9. Miki T, Yano S, Hanibuchi M, Kanematsu T, Muguruma $\mathrm{H}$ and Sone S: Parathyroid hormone-related protein $(\mathrm{PTHrP})$ is responsible for production of bone metastasis, but not visceral metastasis, by human small cell lung cancer SBC-5 cells in natural killer cell-depleted SCID mice. Int J Cancer 108: 511-515, 2004. 
10. Cai Z, Chen Q, Chen J, Lu Y, Xiao G, Wu Z, Zhou Q and Zhang J: Monocyte chemotactic protein 1 promotes lung cancer-induced bone resorptive lesions in vivo. Neoplasia 11: 228-236, 2009.

11. Han JH, Choi SJ, Kurihara N, Koide M, Oba Y and Roodman GD: Macrophage inflammatory protein-1alpha is an osteoclastogenic factor in myeloma that is independent of receptor activator of nuclear factor kappaB ligand. Blood 97: 3349-3353, 2001.

12. Bogenrieder T and Herlyn M: Axis of evil: Molecular mechanisms of cancer metastasis. Oncogene 22: 6524-6536, 2003

13. Reya T, Morrison SJ, Clarke MF and Weissman IL: Stem cells, cancer and cancer stem cells. Nature 414: 105-111, 2001.

14. Vescovi AL, Galli R and Reynolds BA: Brain tumour stem cells. Nat Rev Cancer 6: 425-436, 2006.

15. Driessens G, Beck B, Caauwe A, Simons BD and Blanpain C: Defining the mode of tumour growth by clonal analysis. Nature 488: 527-530, 2012.

16. Al-Hajj M, Wicha MS, Benito-Hernandez A, Morrison SJ and Clarke MF: Prospective identification of tumorigenic breast cancer cells. Proc Natl Acad Sci USA 100: 3983-3988, 2003.

17. Ricci-Vitiani L, Lombardi DG, Pilozzi E, Biffoni M Todaro M, Peschle C and De Maria R: Identification and expansion of human colon-cancer-initiating cells. Nature 445 : 111-115, 2007

18. Todaro M, Perez Alea M, Scopelliti A, Medema JP and Stassi G IL-4 mediated drug resistance in colon cancer stem cells. Cell Cycle 7: 309-313, 2008

19. Hermann PC, Huber SL, Herrler T, Aicher A, Ellwart JW, Guba M, Bruns CJ and Heeschen C: Distinct populations of cancer stem cells determine tumor growth and metastatic activity in human pancreatic cancer. Cell Stem Cell 1: 313-323, 2007.

20. Collins AT and Maitland NJ: Prostate cancer stem cells. Eur J Cancer 42: 1213-1218, 2006.

21. International Stem Cell Initiative, Adewumi O, Aflatoonian B, Ahrlund-Richter L, Amit M, Andrews PW, Beighton G, Bello PA, Benvenisty N, Berry LS, et al: Characterization of human embryonic stem cell lines by the international stem cell initiative. Nat Biotechnol 25: 803-816, 2007.

22. Miki J, Furusato B, Li H, Gu Y, Takahashi H, Egawa S Sesterhenn IA, McLeod DG, Srivastava S and Rhim JS: Identification of putative stem cell markers, CD133 and CXCR4, in hTERT-immortalized primary nonmalignant and malignant tumor-derived human prostate epithelial cell lines and in prostate cancer specimens. Cancer Res 67: 3153-3161, 2007.

23. Singh SK, Hawkins C, Clarke ID, Squire JA, Bayani J, Hide T, Henkelman RM, Cusimano MD and Dirks PB: Identification of human brain tumour initiating cells. Nature 432: 396-401, 2004

24. Eramo A, Lotti F, Sette G, Pilozzi E, Biffoni M, Di Virgilio A, Conticello C, Ruco L, Peschle C and De Maria R: Identification and expansion of the tumorigenic lung cancer stem cell population. Cell Death Differ 15: 504-514, 2008.

25. Dean M, Fojo T and Bates S: Tumour stem cells and drug resistance. Nat Rev Cancer 5: 275-284, 2005.

26. Yu F, Yao H, Zhu P, Zhang X, Pan Q, Gong C, Huang Y, Hu X Su F, Lieberman J and Song E: let-7 regulates self renewal and tumorigenicity of breast cancer cells. Cell 131: 1109-1123, 2007.

27. Levina V, Marrangoni AM, DeMarco R, Gorelik E and Lokshin AE: Drug-selected human lung cancer stem cells: Cytokine network, tumorigenic and metastatic properties. PLoS One 3: e3077, 2008.

28. Yang J and Weinberg RA: Epithelial-mesenchymal transition: At the crossroads of development and tumor metastasis. Dev Cell 14: 818-829, 2008.

29. Thiery JP, Acloque H, Huang RY and Nieto MA Epithelial-mesenchymal transitions in development and disease. Cell 139: 871-890, 2009.

30. Kalluri R and Weinberg RA: The basics of epithelial-mesenchymal transition. J Clin Invest 119: 1420-1428, 2009.

31. Thiery JP: Epithelial-mesenchymal transitions in tumour progression. Nat Rev Cancer 2: 442-454, 2002.

32. Mani SA, Guo W, Liao MJ, Eaton EN, Ayyanan A, Zhou AY, Brooks M, Reinhard F, Zhang CC, Shipitsin M, et al: The epithelial-mesenchymal transition generates cells with properties of stem cells. Cell 133: 704-715,2008.

33. Morel AP, Lièvre M, Thomas C, Hinkal G, Ansieau S and Puisieux A: Generation of breast cancer stem cells through epithelial-mesenchymal transition. PLoS One 3: e2888, 2008.

34. Chaffer CL and Weinberg RA: A perspective on cancer cell metastasis. Science 331: 1559-1564, 2011.
35. Christiansen JJ and Rajasekaran AK: Reassessing epithelial to mesenchymal transition as a prerequisite for carcinoma invasion and metastasis. Cancer Res 66: 8319-8326, 2006.

36. Lacroix M: Significance, detection and markers of disseminated breast cancer cells. Endocr Relat Cancer 13: 1033-1067, 2006.

37. Pantel K, Brakenhoff RH and Brandt B: Detection, clinical relevance and specific biological properties of disseminating tumour cells. Nat Rev Cancer 8: 329-340, 2008.

38. Mego M, Mani SA and Cristofanilli M: Molecular mechanisms of metastasis in breast cancer-clinical applications. Nat Rev Clin Oncol 7: 693-701, 2010.

39. Hou JM, Krebs M, Ward T, Sloane R, Priest L, Hughes A, Clack G, Ranson M, Blackhall F and Dive C: Circulating tumor cells as a window on metastasis biology in lung cancer. Am J Pathol 178: 989-996, 2011.

40. Perl AK, Wilgenbus P, Dahl U, Semb H and Christofori G: A causal role for E-cadherin in the transition from adenoma to carcinoma. Nature 392: 190-193, 1998.

41. Yan B, Zhang W, Jiang LY, Qin WX and Wang X: Reduced E-Cadherin expression is a prognostic biomarker of non-small cell lung cancer: A meta-analysis based on 2395 subjects. Int J Clin Exp Med 7: 4352-4356. 2014.

42. Yang MH, Wu MZ, Chiou SH, Chen PM, Chang SY, Liu CJ, Teng SC and Wu KJ: Direct regulation of TWIST by HIF-1alpha promotes metastasis. Nat Cell Biol 10: 295-305, 2008

43. Sánchez-Tilló E, Lázaro A, Torrent R, Cuatrecasas M, Vaquero EC, Castells A, Engel P and Postigo A: ZEB1 represses E-cadherin and induces an EMT by recruiting the SWI/SNF chromatin remodeling protein BRG1. Oncogene 29: 3490-3500, 2010.

44. Ko H, Jeon H, Lee D, Choi HK, Kang KS and Choi KC: Sanguiin H6 suppresses TGF- $\beta$ induction of the epithelial-mesenchymal transition and inhibits migration and invasion in A549 lung cancer. Bioorg Med Chem Lett 25: 5508-5513. 2015.

45. Yang X, Li L, Huang Q, Xu W, Cai X, Zhang J, Yan W, Song D, Liu T, Zhou W, et al: Wnt signaling through Snaill and Zeb1 regulates bone metastasis in lung cancer. Am J Cancer Res 5: 748-755, 2015

46. Gilkes DM, Semenza GL and Wirtz D: Hypoxia and the extracellular matrix: Drivers of tumour metastasis. Nat Rev Cancer 14 430-439, 2014.

47. Joyce JA: Therapeutic targeting of the tumor microenvironment. Cancer Cell 7: 513-520, 2005.

48. Lewis CE and Pollard JW: Distinct role of macrophages in different tumor microenvironments. Cancer Res 66: 605-612, 2006.

49. Coussens LM, Fingleton B and Matrisian LM: Matrix metalloproteinase inhibitors and cancer: Trials and tribulations. Science 295: 2387-2392, 2002.

50. Hu T and Lu YR: BCYRN1, a c-MYC-activated long non-coding RNA, regulates cell metastasis of non-small-cell lung Cancer. Cancer Cell Int 15: 36, 2015.

51. Hsu CP, Shen GH and Ko JL: Matrix metalloproteinase-13 expression is associated with bone marrow microinvolvement and prognosis in non-small cell lung cancer. Lung Cancer 52: 349-357, 2006

52. Wang H, Zhu Y, Zhao M, Wu C, Zhang P, Tang L, Zhang H, Chen X, Yang Y and Liu G: miRNA-29c suppresses lung cancer cell adhesion to extracellular matrix and metastasis by targeting integrin $\beta 1$ and matrix metalloproteinase2 (MMP2). PloS One 8: e70192, 2013.

53. Papetti $M$ and Herman IM: Mechanisms of normal and tumor-derived angiogenesis. Am J Physiol Cell Physiol 282: C947-C970, 2002.

54. Dimova I, Popivanov G and Djonov V: Angiogenesis in cancer-general pathways and their therapeutic implications. J BUON 19: 15-21, 2014.

55. Weis SM and Cheresh DA: $\alpha \mathrm{V}$ integrins in angiogenesis and cancer. Cold Spring Harb Perspect Med 1: a006478, 2011

56. Young R, Pailler E, Billiot F, Drusch F, Barthelemy A, Oulhen M, Besse B, Soria JC, Farace F and Vielh P: Circulating tumor cells in lung cancer. Acta Cytol 56: 655-660, 2012.

57. O'Flaherty JD, Gray S, Richard D, Fennell D, O'Leary JJ, Blackhall FH and O'Byrne KJ: Circulating tumour cells, their role in metastasis and their clinical utility in lung cancer. Lung Cancer 76: 19-25, 2012.

58. Parkinson DR, Dracopoli N, Petty BG, Compton C, Cristofanilli M, Deisseroth A, Hayes DF, Kapke G, Kumar P, Lee JSh, et al: Considerations in the development of circulating tumor cell technology for clinical use. J Transl Med 10: 138, 2012. 
59. Tanaka F, Yoneda K, Kondo N, Hashimoto M, Takuwa T, Matsumoto S, Okumura Y, Rahman S, Tsubota N, Tsujimura T, et al: Circulating tumor cell as a diagnostic marker in primary lung cancer. Clin Cancer Res 15: 6980-6986, 2009.

60. Hou JM, Greystoke A, Lancashire L, Cummings J, Ward T, Board R, Amir E, Hughes S, Krebs M, Hughes A, et al: Evaluation of circulating tumor cells and serological cell death biomarkers in small cell lung cancer patients undergoing chemotherapy. Am J Pathol 175: 808-816, 2009.

61. Hofman V, Long E, Ilie M, Bonnetaud C, Vignaud JM, Fléjou JF, Lantuejoul S, Piaton E, Mourad N, Butori C, et al: Morphological analysis of circulating tumour cells in patients undergoing surgery for non-small cell lung carcinoma using the isolation by size of epithelial tumour cell (ISET) method. Cytopathology 23 : 30-38, 2012.

62. Nieva J, Wendel M, Luttgen MS, Marrinucci D, Bazhenova L, Kolatkar A, Santala R, Whittenberger B, Burke J, Torrey M, et al: High-definition imaging of circulating tumor cells and associated cellular events in non-small cell lung cancer patients: A longitudinal analysis. Phys Biol 9: 016004, 2012

63. Palumbo JS, Talmage KE, Massari JV, La Jeunesse CM, Flick MJ, Kombrinck KW, Hu Z, Barney KA and Degen JL: Tumor cell-associated tissue factor and circulating hemostatic factors cooperate to increase metastatic potential through natura killer cell-dependent and-independent mechanisms. Blood 110 133-141, 2007.

64. Schumacher D, Strilic B, Sivaraj KK, Wettschureck N and Offermanns S: Platelet-derived nucleotides promote tumor-cell transendothelial migration and metastasis via $\mathrm{P} 2 \mathrm{Y} 2$ receptor Cancer Cell 24: 130-137, 2013.

65. Hou JM, Krebs M, Ward T, Sloane R, Priest L, Hughes A, Clack G, Ranson M, Blackhall F and Dive C: Circulating tumor cells as a window on metastasis biology in lung cancer. Am J Pathol 178: 989-996, 2011.

66. Stone JP and Wagner DD: P-selectin mediates adhesion of platelets to neuroblastoma and small cell lung cancer. J Clin Invest 92: 804-813, 1993.

67. Coleman RE: Skeletal complications of malignancy. Cancer 80 (Suppl 8): S1588-S1594. 1997.

68. Hart IR and Fidler IJ: Role of organ selectivity in the determination of metastatic patterns of B16 melanoma. Cancer Res 40 2281-2287, 1980

69. Stetler-Stevenson WG and Kleiner DEJ: Molecular biology of cancer: Invasion and metastases. Cancer: Principles and Practice of Oncology 6: 123-136, 2001.

70. Müller A, Homey B, Soto H, Ge N, Catron D, Buchanan ME, McClanahan T, Murphy E, Yuan W, Wagner SN, et al: Involvement of chemokine receptors in breast cancer metastasis. Nature 410: 50-56, 2001

71. Richert MM, Vaidya KS, Mills CN, Wong D, Korz W, Hurst DR and Welch DR: Inhibition of CXCR4 by CTCE-9908 inhibits breast cancer metastasis to lung and bone. Oncol Rep 21: 761-767, 2009.

72. Smith MC, Luker KE, Garbow JR, Prior JL, Jackson E, Piwnica-Worms D and Luker GD: CXCR4 regulates growth of both primary and metastatic breast cancer. Cancer Res 64 8604-8612, 2004.

73. Phillips RJ, Burdick MD, Lutz M, Belperio JA, Keane MP and Strieter RM: The stromal derived factor-1/CXCL12-CXC chemokine receptor 4 biological axis in non-small cell lung cancer metastases. Am J Respir Crit Care Med 167: 1676-1686, 2003.

74. Hirbe AC, Rubin J, Uluçkan O, Morgan EA, Eagleton MC, Prior JL, Piwnica-Worms D and Weilbaecher KN: Disruption of CXCR4 enhances osteoclastogenesis and tumor growth in bone. Proc Natl Acad Sci USA 104: 14062-14067, 2007.

75. Hirbe AC, Morgan EA and Weilbaecher KN: The CXCR4/SDF-1 chemokine axis: A potential therapeutic target for bone metastases? Curr Pharm Des 16: 1284-1290, 2010.

76. Nakamura ES, Koizumi K, Kobayashi M, Saitoh Y, Arita Y, Nakayama T, Sakurai H, Yoshie O and Saiki I: RANKL-induced CCL22/macrophage-derived chemokine produced from osteoclasts potentially promotes the bone metastasis of lung cancer expressing its receptor CCR4. Clin Exp Metastasis 23: 9-18, 2006.

77. Burns JM, Summers BC, Wang Y, Melikian A, Berahovich R, Miao Z, Penfold ME, Sunshine MJ, Littman DR, Kuo CJ, et al: A novel chemokine receptor for SDF-1 and I-TAC involved in cell survival, cell adhesion and tumor development. J Exp Med 203: 2201-2213, 2006.
78. Lee JH, Kim HN, Kim KO, Jin WJ, Lee S, Kim HH, Ha H and Lee ZH: CXCL10 promotes osteolytic bone metastasis by enhancing cancer outgrowth and osteoclastogenesis. Cancer Res 72: 3175-3186, 2012

79. Li N, Zhang JP, Guo S, Min J, Liu LL, Su HC, Feng YM and Zhang HL: Down-regulation of $\beta 3$-integrin inhibits bone metastasis of small cell lung cancer. Mol Biol Rep 39: 3029-3035, 2012.

80. Yin $\mathrm{H}$ and Deng $\mathrm{J}$ : Advances in lung stem cells and lung cancer stem cells. Zhongguo Fei Ai Za Zhi 18: 633-639, 2015 (In Chinese).

81. Hiraga T, Ito $\mathrm{S}$ and Nakamura $\mathrm{H}$ : Cancer stem-like cell marker CD44 promotes bone metastases by enhancing tumorigenicity, cell motility and hyaluronan production. Cancer Res 73: 4112-4122, 2013

82. Deng X, Tannehill-Gregg SH, Nadella MV, He G, Levine A, Cao Y and Rosol TJ: Parathyroid hormone-related protein and ezrin are up-regulated in human lung cancer bone metastases. Clin Exp Metastasis 24: 107-119, 2007.

83. Li M,Amizuka N, Takeuchi K, Freitas PH, Kawano Y,Hoshino M, Oda K, Nozawa-Inoue K and Maeda T: Histochemical evidence of osteoclastic degradation of extracellular matrix in osteolytic metastasis originating from human lung small carcinoma (SBC-5) cells. Microsc Res Tech 69: 73-83, 2006.

84. Yoneda T and Hiraga T: Crosstalk between cancer cells and bone microenvironment in bone metastasis. Biochem Biophys Res Commun 328: 679-687, 2005.

85. Zhang F, Wang Y, Xu M, Dong H, Liu N, Zhou J, Pang H, Ma N, Zhang N, Pei Y, et al: MGrl-Ag promotes invasion and bone metastasis of small-cell lung cancer in vitro and in vivo. Oncol Rep 29: 2283-2290, 2013.

86. Alves F, Vogel W, Mossie K, Millauer B, Höfler H and Ullrich A: Distinct structural characteristics of discoidin I subfamily receptor tyrosine kinases and complementary expression in human cancer. Oncogene 10: 609-618, 1995.

87. Valencia K, Ormazábal C, Zandueta C, Luis-Ravelo D, Antón I, Pajares MJ, Agorreta J, Montuenga LM, Martínez-Canarias S, Leitinger B and Lecanda F: Inhibition of collagen receptor discoidin domain receptor-1 (DDR1) reduces cell survival, homing, and colonization in lung cancer bone metastasis. Clin Cancer Res 18: 969-980, 2012.

88. Catena R,Luis-Ravelo D, Antón I,Zandueta C, Salazar-Colocho P, Larzábal L, Calvo A and Lecanda F: PDGFR signaling blockade in marrow stroma impairs lung cancer bone metastasis. Cancer Res 71: 164-174, 2011.

89. Sela J: Bone remodeling in pathological conditions. A scanning electron microscopic study. Calcif Tissue Res 23: 229-234, 1977.

90. Boyde A, Maconnachie E, Reid SA, Delling G and Mundy GR: Scanning electron microscopy in bone pathology: Review of methods, potential and applications. Scan Electron Microsc: $1537-1554,1986$

91. Guise TA: The vicious cycle of bone metastases. J Musculoskelet Neuronal Interact 2: 570-572, 2002.

92. Karapanagiotou EM, Terpos E, Dilana KD, Alamara C, Gkiozos I, Polyzos A and Syrigos KN: Serum bone turnover markers may be involved in the metastatic potential of lung cancer patients. Med Oncol 27: 332-338, 2010.

93. Peng X, Guo W, Ren T, Lou Z, Lu X, Zhang S, Lu Q and Sun Y: Differential expression of the RANKL/RANK/OPG system is associated with bone metastasis in human non-small cell lung cancer. PLoS One 8: e58361, 2013.

94. Feeley BT, Liu NQ, Conduah AH, Krenek L, Roth K, Dougall WC, Huard J, Dubinett $S$ and Lieberman JR: Mixed metastatic lung cancer lesions in bone are inhibited by noggin overexpression and Rank: Fo administration. J Bone Miner Res 21: 1571-1580, 2006.

95. Bundred NJ, Walker RA, Ratcliffe WA, Warwick J, Morrison JM and Ratcliffe JG: Parathyroid hormone related protein and skeletal morbidity in breast cancer. Eur J Cancer 28: 690-692, 1992.

96. Burton DW, Geller J, Yang M, Jiang P, Barken I, Hastings RH, Hoffman RM and Deftos LJ: Monitoring of skeletal progression of prostate cancer by GFP imaging, X-ray and serum OPG and PTHrP. Prostate 62: 275-281, 2005.

97. Miki T, Yano S, Hanibuchi M, Kanematsu T, Muguruma H and Sone S: Parathyroid hormone-related protein $(\mathrm{PTHrP})$ is responsible for production of bone metastasis, but not visceral metastasis, by human small cell lung cancer SBC-5 cells in natural killer cell-depleted SCID mice. Int J Cancer 108: 511-515, 2004.

98. Muguruma H, Yano S, Kakiuchi S, Uehara H, Kawatani M, Osada $\mathrm{H}$ and Sone S: Reveromycin A inhibits osteolytic bone metastasis of small-cell lung cancer cells, SBC-5, through an antiosteoclastic activity. Clin Cancer Res 11: 8822-8828, 2005. 
99. Iguchi H, Tanaka S, Ozawa Y, Kashiwakuma T, Kimura T, Hiraga T, Ozawa T and Kono T: An experimental model of bone metastasis by human lung cancer cells: The role of parathyroid hormone-related protein in bone metastasis. Cancer Res 56: 4040-4043, 1996.

100.Lorch G, Gilmore JL, Koltz PF, Gonterman RM, Laughner R, Lewis DA, Konger RL, Nadella KS, Toribio RE, Rosol TJ and Foley J: Inhibition of epidermal growth factor receptor signalling reduces hypercalcaemia induced by human lung squamous-cell carcinoma in athymic mice. Br J Cancer 97: 183-193, 2007.

101.Herroon MK, Rajagurubandara E, Rudy DL, Chalasani A, Hardaway AL and Podgorski I: Macrophage cathepsin K promotes prostate tumor progression in bone. Oncogene 32 : 1580-1593, 2013.

102.Lawrence T and Natoli G: Transcriptional regulation of macrophage polarization: Enabling diversity with identity. Nat Rev Immunol 11: 750-761, 2011.

103.Zhang M, He Y, Sun X, Li Q, Wang W, Zhao A and Di W: A high $\mathrm{M} 1 / \mathrm{M} 2$ ratio of tumor-associated macrophages is associated with extended survival in ovarian cancer patients. J Ovarian Res 7: 19, 2014.

104.Hiraoka K, Zenmyo M, Watari K, Iguchi H, Fotovati A, Kimura YN, Hosoi F, Shoda T, Nagata K, Osada H, et al: Inhibition of bone and muscle metastases of lung cancer cells by a decrease in the number of monocytes/macrophages. Cancer Sci 99: 1595-1602, 2008.

105. Krzeszinski JY and Wan Y: New therapeutic targets for cancer bone metastasis. Trends Pharmacol Sci 36: 360-373, 2015.
106. Antón I, Molina E, Luis-Ravelo D, Zandueta C, Valencia K, Ormazabal C, Martínez-Canarias S, Perurena N, Pajares MJ, Agorreta $\mathrm{J}$, et al: Receptor of activated protein $\mathrm{C}$ promotes metastasis and correlates with clinical outcome in lung adenocarcinoma. Am J Respir Crit Care Med 186: 96-105, 2012.

107. Luis-Ravelo D, Antón I, Zandueta C, Valencia K, Ormazábal C, Martínez-Canarias S, Guruceaga E, Perurena N, Vicent S, De Las Rivas J and Lecanda F: A gene signature of bone metastatic colonization sensitizes for tumor-induced osteolysis and predicts survival in lung cancer. Oncogene 33: 5090-5099, 2014.

108. Nguyen DX, Chiang AC, Zhang XH, Kim JY, Kris MG, Ladanyi M, Gerald WL and Massagué J: WNT/TCF signaling through LEF1 and HOXB9 mediates lung adenocarcinoma metastasis. Cell 138: 51-62, 2009.

109. Gong M, Ma J, Guillemette R, Zhou M, Yang Y, Yang Y, Hock JM and Yu X: miR-335 inhibits small cell lung cancer bone metastases via IGF-IR and RANKL pathways. Mol Cancer Res 12: 101-110, 2014.

110. Valencia K, Martín-Fernández M, Zandueta C, Ormazábal C, Martínez-Canarias S, Bandrés E, de la Piedra C and Lecanda F: miR-326 associates with biochemical markers of bone turnover in lung cancer bone metastasis. Bone 52: 532-539, 2013.

111. Ell B and Kang Y: MicroRNAs as regulators of bone homeostasis and bone metastasis. Bonekey Rep 3, 549, 2014.

112. Napoli LD, Hansen HH, Muggia FM and Twigg HL: The incidence of osseous involvement in lung cancer, with special reference to the development of osteoblastic changes. Radiology 108: 17-21, 1973. 